\title{
Partnership Law and its spawn: did the LLP form deliver on its promises?
}

\begin{abstract}
Institutional theory discusses whether organizations increase their profitability and sustainability by converging around socially legitimated forms. This study contributes to the literature by examining the benefits of strategic choices (legal form) of accounting firms. The results suggest that the change in percentage of income from audit activities is different for partnerships than LLP firms. Inflation (CPI) adjusted revenues (fees per partner) is not statistically different from 2005 to 2013 . We also observe that spread of offices, specialisation and the degree of hierarchy lead to efficiencies of operations and wealth enhancement (through changes in Revenues (Fees) per partner) but 'LLP choice' per se does not necessarily increase fees.
\end{abstract}




\section{Partnership Law and its spawn: did LLP deliver on its promises?}

\section{Introduction}

"Professional service firms exist at the interstices of multiple institutional fields, simultaneously defending the interests of commerce, the state, and society."

(Suddaby et al 2008 p. 990)

It has now long been recognised that the largest professional accounting firms, firms which had from their inception a primary objective of serving the public interest, have shifted to essentially entrepreneurial operations (Hopwood 1985). The key aspects of the legal form of a partnership had long been that partners are jointly and severally liable, and liability claims are potentially unlimited. In the period of the late 1990s, when the UK accounting firms could not get any traction to shift the UK Government's recalcitrance against the introduction of any Limited Liability Partnership (LLP) legislation (as had already occurred in the USA), two large firms (EY and PWC) pushed legislators in the Channel Island of Jersey to allow such legal structures (Greenwood and Empson 2003, page 911, Likierman 1989). Specifically, in 1996 it was reported that EY had "threatened to move its (UK) headquarters to Jersey" (Sikka and Wilmott citing The Guardian).

At the time of the start of the LLP introduction in Jersey, PWC senior partner Ian Brindle said that "he had not dismissed the idea of incorporation, but that he was loth[sic] to lose the partnership ethos and get rid of the partners' personal and financial interest in the business. 'Our partnership is very special,' he said, 'and you change it at your peril.' 'It is our preferred option at this stage,' said Ernst \& Young's senior partner Nick Land. 'We rejected partial incorporation twelve months ago as ineffective and not suited to our culture'"' (Anon, Accountancy Age, 1996). But regulatory constraints, on their own, do not explain why nearly all large accounting firms have chosen to retain the partnership form, even as an LLP, and why it is still also popular among management consulting and architectural service firms.

In the light of the resistance to permitting the LLP form from the UK government in the early 1990s, the largest firms did not consider changing to a corporate form, but instead these largest of all global partnerships argued that the general partnership law is no longer an appropriate vehicle on grounds of sustainability and following extensive lobbying, a new vehicle, the LLP, was introduced limiting partners' exposure to risk in Jersey, Channel Islands (Sikka \& Willmott, 2009; Boatright, 2007; Sikka, 2008). Partners of large accounting firms threatened to take their operations "off-shore". The UK Government then back-tracked and hastily passed close to what the large firms had been seeking ten years earlier.

LLP represents a 'half-way' house between pure partnership and limited liability companies. Some research already undertaken in this includes that of Lennox and Li (2012), basing their study on data in company reports, and asking: Is audit quality impaired after audit partners obtain limited liability? Do clients perceive that they suffer adverse consequences when partners are protected by limited liability? Do auditors become more tolerant of client litigation risk after they switch to limited liability? Lennox and Li (2012) find that the probability of an audit firm switching to LLP is increasing in its size and litigation exposure. The evidence does not support that audit firms supply lower quality audits, lose market share or charge lower audit fees after becoming LLPs. They do find a shift towards riskier public traded companies within the portfolio of clients 
after a switch to LLP. A regulatory change that allows audit firms to choose whether LLP adoption is optimal for them clearly has some effects but there may be other strategic effects that can only be observed with a finer, or different, dataset.

Therefore, this study takes a very different approach to prior work that is largely based on company data. Motivated by Morris and Pinnington (2003), we examine a cross section sample of accounting firm data in 2005 and 2013, for reasons as further described. Using the publically available data-set of the Top 50 accounting firm data since 2005 published annually in Accountancy Age, we reflected on what was promised with LLP. The research questions are: are there any benefits for client firms of accounting partnerships with the introduction of LLP, judged by revenue streams from audit activity? What can we determine about firm profitability when there is a shift to LLP, and its possible impact on audit fees and revenues? In analysis of firm revenues and associated data, and given that the one of the promises of LLP was to reduce liability costs, we interrogate these questions through offering three postulates:

i. Given that insurance costs would not increase as much as other expenses, then total (CPI adjusted) revenues for the firms in the UK Top 50 would increase over the period $2005-2013$.

ii. That there may also be associated proxies for strategic choices that further clarify what were specific drivers to changes in Revenues (Fees) per partner and the 'LLP choice'.

iii. That the reduction of liability and (conjectured) cheaper insurance would permit a reduction in audit fees; and therefore the proportion of revenues earned from specialised audit activities would reduce compared with total revenue, based on accounting firm data.

In order to answer the questions, and based on these postulates, this paper proceeds as follows: we offer some brief history of regulation of accounting firms, and review what was promised with the introduction of LLP, and suggest that this analysis can be best located within a contingency theory approach. We then undertake statistical analysis based on 2005 and 2013 firm data across the Top 50 firms in the UK, ending with some discussion which can be seen to challenge other perspectives on firm success and growth of the Top 50 firms in the UK.

\section{History}

Corporations had been used from the end of the sixteenth century and were created by the Crown granting charters of incorporation. They were legal entities distinct from their members, who were theoretically not liable for their debts. However, this limited liability was illusory in practice as the corporation would call on its members to meet its debts. This form of incorporation relies on multiple theoretical backgrounds and comes with the expense and delay of attaining a charter (Veldman, 2013; Mackenzie, 2008).

From 1844 it became far easier to form a company that was a separate legal entity from its owners. However, the Joint Stock Companies Act 1844 expressly preserved the full personal liability of members for company debts. A further eleven years went by before this changed. The enactment of the United Kingdom Limited Liability Act of 1855 granted companies limited liability. Such freedom from liability did not pass to partnerships, as being in a partnership meant it was not recognised in law as a separate entity from its partners (Mackenzie 2008), although it was specifically the 1948 Companies Act 1948 which prohibited company auditors from trading through limited liability entities (Sikka and Willmott, 2009). 
In other EU member states which have a limited liability regime for auditors, "the limitation mechanisms were either in the form of: a financial cap on the level of possible liability claims (as in the case of Austria, Belgium, Germany, Greece, and Slovenia); a system of proportionate liability whereby auditors are liable only for the damages caused directly as a result of their negligent behaviour (as in Spain); or by allowing auditors to establish limited liability entities" (Samsonova-Taddei and Humphrey, 2015). Before the LLP legislation, the only option to a partnership was the PLC option, and in the UK KPMG was the first accounting firm that, in 1995, had chosen to incorporate and form what became known as KPMG Audit PLC (Samsonova-Taddei and Humphrey, 2015).

Sikka (2008) offered an invaluable case study relating to the evolution between 1995 and 1998 of the LLP legislation in Jersey, a UK Crown Dependency. Jersey, offshore to the UK, and part of the Channel Islands in the English Channel, is neither part of the UK nor a member of the European Union (EU) and therefore not subject to any British or EU laws. Sikka's study "provided further evidence of the race-to-the-bottom embedded in economic globalization and inherent in a system of jurisdictionally bound competing nation states" (2008 page 418). This was followed by further analysis in the Sikka and Wilmott (2009) review.

The large accounting firms were continually stone-walled in their attempts to get such legislation in the UK, and therefore threatened to move their head offices to the Channel Islands and take advantage of the more favourable and sympathetic legislation promised be offered there. In a very public effort to generate more business activities based in Jersey, on 11th December 1995, the States of Jersey announced that the FEC proposed to introduce LLP legislation; the 1996 LLP Bill was drafted for the Jersey legislature by the UK offices of Ernst \& Young and Price Waterhouse.

Such arrangements persuaded some to argue that Jersey was offering its "legislature for hire" to enable major accountancy firms (as a fraction of international capital) to hold other nation-states, e.g. the UK, to ransom (Hampton and Christensen, 1999). The approach to Jersey was made at a time (mid-1990s) when major accountancy firms were facing a number of high profile lawsuits arising out of real/alleged audit failures and campaigning to secure liability concessions from the UK government (Cousins et al., 1999). (Sikka 2008)

Given these events, the UK government promised equivalent legislation within a week (Financial Times, 1996) then later "at the earliest opportunity (Hansard, 1996). Eventually, it issued a consultation paper on creating Limited Liability Partnerships (UK Department of Trade and Industry, 1997), followed by a Bill (in 1998) and an Act[26] (Limited Liability Partnerships Act 2000) which came into force on 6 April 2001". (Sikka 2008 page 414)

The reason for this had little to do with the pros and cons of public interest arguments which had earlier prevailed in debates against the introduction of such law; but everything to do with the effective threats of the largest Big 4 firms to shift their head office to the Channel Islands.

\section{Given the choice, would all firms follow the Big 4?}


Bearing in mind much commentary after this UK legislation was passed was not specific to the field of accounting and accountancy firms, the uptake of the LLP structure was slower than had been anticipated. Before the enactment of LLP legislation in the UK, accounting partnerships showed some selection from diverse drivers to differential survival, but did not exhibit strong selective pressures that favoured one form or structure over another (McMeeking, 2009) with the exception of the use by, for example, KPMG of an Audit PLC, as mentioned above. They mostly retained partnership forms, even with its downside of liability.

Then for a brief period after the enactment of the LLP legislation, it is very likely that all firms assessed the increased choice of permitted structures. The shift to the LLP structure by all of the largest firms occurred between the period 2002 and 2005 . The largest firm not to adopt an LLP or corporate structure as at 2004 was PKF, ranked number 8 in the list of fee revenues of the largest UK accounting firms. In 2005 there were 17 firms in the Top 50 described as LLPs. However, we now observe a variety of structural forms in the Top 50. Based on 2013 data in Accountancy Age Top 50:

\section{Table 1: Variety of structural forms (2013)}

\begin{tabular}{|l|c|}
\hline 2013 structures were described as a \\
\hline LLP & 28 \\
\hline Partnership & 8 \\
\hline PLC & 3 \\
\hline Mixture & 2 \\
\hline LTD & 2 \\
\hline Association & 2 \\
\hline n/a & 2 \\
\hline Network & 1 \\
\hline Franchise & 1 \\
\hline unlisted PLC with an LLP & 1 \\
\hline & 50 \\
\hline
\end{tabular}

It is clear that the opportunity for flexibility in structural choices has been taken advantage of, depending on the strategic choices of each firm. Young (2000) described the drivers of the legislation were specific to:

- Increasing frequency and size of professional negligence claims;

- Risks to partners' assets after the firms' assets and/or insurance cover has been exhausted;

- Structural requirements of businesses with very large numbers of partners;

- Increasing specialisation within one umbrella business unit;

- Mixing of different professions and skills within firms.

"In doing so, it avowed that the price of such relaxation in liability is transparency, in accounting and operating terms" (Young 2000). The driver to the Big 4 pushing so hard for this was more simply expressed as: the law will enable accounting firms to protect its individual partners' personal assets from damages awards against their firm (Anon, Accountancy, 16 ${ }^{\text {th }}$ Jan. 1996). Urgency was added by a 1995 High Court damages award against the former partnership of BDO Binder Hamlyn (ibid) and the subsequent collapse of Andersen. There was further discussion of these perceived promises; but there was 
also opposition which had been continuing since the 1980s, but was perhaps worn down by attrition.

\section{What Opposition?}

MP Austin Mitchell attempted to prevent the Jersey law going through. "He tabled an early day motion last month [November 1996] urging rejection of the Bill because of 'the protection which that law gives to bad auditors and failed audits, its reduction of rights of consumers of accounts to enhance the rights of a powerful vested interest and absolve them from the consequences of their own failure'. The only hitch as far as the firms are concerned is a surprise move by the Inland Revenue" (Accountancy 12th Dec. 1996).

HMRC had recommended that Jersey LLPs 'may' be taxed as if they were companies. Three years after the Jersey Law had been passed, support in the UK was cross-party, though not universal. In the light of the eventual HMRC decision, Jersey had become effectively out of bounds for UK firms "unless they are prepared to take the massive financial hit that being taxed as a company, rather than a partnership, would involve. This was estimated at a $7 \%$ to $10 \%$ rise in their tax bills, in addition to a significant one-off capital gains tax charge" (Accountancy International June 1999).

Arch-opponent Lord Philips of Sudbury, a solicitor, suggested LLP would "provide your two-man cowboy building outfit with a uniquely flexible and light framed means of screwing the public'" (Young 2000).

The UK legislation passed to be effective from April 6th 2001. But in 2001, a spokesman for Companies House conceded that he was 'not expecting a big rush'. He added:

'Our market research indicates a high level of public awareness, particularly in primary professions such as lawyers and accountants.' He went on to say that Companies House research indicated the attraction of limited liability seems to lie in the protection it offers individual partners, mainly because the current situation makes it difficult for firms to attract new partners. Most respondents saw the greater disclosure demands under LLPs over standard partnerships as an acceptable trade-off for this protection. (Quick, 2001).

\section{With the benefit of hindsight}

The current drive for transparency by the UK government has some impact on LLPs: in April 2014 it was made clear in UK proposals that it will no longer be possible to have a corporate director of a company, and that this will apply to LLPs i.e. all directors will need to be natural persons (Cearns 2014). The LLP Act (2000) had recognised that members of LLPs are at the same time owners, managers and workers. Effectively the roles of director and shareholder are combined. Cearns (2014) predicts that if the UK government proposals in April 2014 are not changed during deliberation on the legislation, then many LLPs would have to 'unwind'. Murray et al. (2014) also asked: was LLP losing its shine? They identified three attacks on LLPs: tax changes, a ruling from the Supreme Court that LLP members were 'workers'; and the 'natural persons' proposal, as described above. These challenges undermine the attractiveness of LLP structures and it is gradually becoming clearer that LLP is a far less attractive structure than when it was first introduced in 2000 for all professional firm categories. 


\section{A contingency theory approach}

Theorising the analysis of the shift to the LLP form in this study is located within contingency theory. Table one above shows a variety of responses to the opportunities provided, as all firms in the 'Top 50' faced a change in external conditions (litigation exposure) with a theoretical advantage of a niche industry specialisation (Hickson et al., 1971; Van de Ven and Drazin, 1984). Consistent with the option to change to the LLP form, Tushman and Romanelli (1985) suggest there may be a correlation between survival and strategic reorientation, but their analysis implies that this correlation should be present only for organizations that have a relatively high intensity of epistatic interactions. Professional service firms were experiencing major changes in their regulatory and market contexts and cyclical demands and shifts in organizational power (Whittington et al., 2011).

Nearly all large firms are continuing to expand internationally, putting pressures upon traditional managerial practices. Organizational structures and cultures are becoming increasingly complex, exacerbating challenges of co-ordination. Boundaries between professional specializations are becoming blurred, complicating decision processes. (Suddaby et al 2008 p. 990)

This confirms the utility of contingency theory in this study. They state the empirical contexts in their own study cover actuarial, advertising, architects, consulting, law, engineering and security analysts in that issue; but using data from two accounting firms and one actuarial firm. Litrico and Lee (2008) examine a central issue confronting professional service firms: the need to balance the characteristic high work pressures with demands for "alternative work arrangements." Institutional theory focuses upon how organizations enhance their survival by converging around socially legitimated forms (DiMaggio and Powell 1991). These perspectives combine two tasks: both identifying and also explaining organizational variation. It may be that in recent years more attention has been given to the latter than the former, but there has been increasing interest in discerning hitherto neglected forms (Aldrich 1999); and this study contributes to that debate.

\section{Table 2: Forms of Governance in Professional Services Firms (from Greenwood and Empson)}

Greenwood \& Empson: The Professional Partnership

\begin{tabular}{llllll}
$\begin{array}{l}\text { Table } 1 \\
\text { Forms of } \\
\text { Governance in }\end{array}$ & $\begin{array}{l}\text { Professional } \\
\text { Professional }\end{array}$ & $\begin{array}{l}\text { Firms } \\
\text { (number) }\end{array}$ & $\begin{array}{l}\text { Partnerships } \\
(\%)\end{array}$ & $\begin{array}{l}\text { Private } \\
\text { corporations (\%) }\end{array}$ & $\begin{array}{l}\text { Public } \\
\text { corporations (\%) }\end{array}$ \\
\cline { 2 - 5 } $\begin{array}{l}\text { Services Firms } \\
\text { Top 100 Firms }\end{array}$ & $\begin{array}{l}\text { Law } \\
\text { Accounting }\end{array}$ & 100 & 100 & 0 & 0 \\
Globally by & $\begin{array}{l}\text { Management } \\
\text { consulting }\end{array}$ & 100 & 56 & 42 & 2 \\
& Advertising & 100 & 17 & 44 & 39 \\
& Architecture & 100 & 0 & 77 & 23 \\
& & 18 & 73 & 9 \\
\hline
\end{tabular}

Source: Consultants News, Public Accounting Report, American Lawyer, Advertising Age, World Architecture Magazine and websites.

This variety noted for a range of professional firms is further reflected in our Table one: the same range and diversity of choices having been taking advantage of by accounting 
professional firms in the Top 50 in 2013. It is not the place in this study to examine the degree of concentration across professions, and the drivers behind the growth of the Big 4 Accounting firms in capturing/monopolising the audit market in particular. They have advantages over others - for instance, law firms are conflicted out from some revenue streams, whereas one accounting firm could theoretically (and in practice does) command all of the revenue from an industry in which it had chosen to specialise. But sufficient of this literature has been offered to proceed to the data analysis.

\section{Data Analysis}

We chose analysis of firm revenues and associated data based on two years of data: 2005 (covered reporting periods for these entities from end of June 2004 (PWC) - end of June 2005 (EY)) and 2013. Data for this research are hand collected from the annual reports of the 'Top 50' accounting firms identified in Accountancy Age from 2005 - 2013. We did not have access to go back earlier than 2005, and even then, some of the 2005 data is patchy and does not cover with the same detail as the later ranking Tables. The 2013 data covered reporting dates for the years ending 31/05/2012 (Deloitte) up to 30/04/2013.

This period of comparison is also of interest, as it was before and after the Global Financial Crisis, where there was a significant drop in all revenues for accounting firms. Choosing 2005 and 2013 for this analysis has attempted to bridge that period of loss and regain in fee income. The period is also interesting because of the aforementioned legislation, and the considerable growth opportunities within the sector associated with the adoption of International Financial Reporting Standards by corporates across Europe (from 1 January 2005).

Analysis was based on data representing:

- Revenues (Fees) per partner is expressed in pounds sterling, these were converted by a factor of .796 to ensure comparability with 2005 data i.e. inflation adjusted.

- $\quad$ Size (small, medium, large)

- In 2005 this division as reflected in Revenues for Small of $£ 9$ - $£ 12$ million, Medium were $£ 22$ - $£ 32$ million, and Large had revenues of $£ 1,297-£ 2,086$ million. Five firms were selected in each of the small to medium groups, and the Big 4 were the large firms.

- In 2013 this division as reflected in Revenues for Small of $£ 12-£ 15$ million, Medium were $£ 28-£ 40$ million, and Large had revenues of $£ 1,630-£ 2,329$ million. Five firms were selected in each of the small to medium groups, and the Big 4 were the large firms.

- Type (LLP, partnership)

- Year $(2005,2013)$

- Density is the number of partners per office

- Fees per non-partner Staff (Professional only) is similar to a ratio of return on investment in non-partner staff

- Hierarchy is the number of staff per partner

- Feesoffice is the ratio of fees per office and is similar to a Return on assets measure

- Special is the proportion of Fee revenue from the largest segment of operations, (usually audit but tax for some firms). 
Unreported descriptive statistics did not reveal any of the basic econometric problems, e.g. hetroskedasticity and non-normality. Multicollinearity diagnostics show that all independent variables had acceptable VIF and Tolerance values.

\section{Results:}

The first section of the analysis examines two research questions:

1. Are there associated proxies for strategic choices that further clarify what were specific drivers to changes in Revenues (Fees) per partner and the 'LLP choice'?

2. Did total (CPI adjusted) revenues/fees for the firms within the Top 50 increase over the period $2005-2013$ ?

We first test what strategic choices were drivers to changes in revenues per partner. Table three presents the results of a two-way ANOVA (i.e. tests of between-subjects effects) with Revenues (Fees) per partner as the dependent variable, the first three predictor variables as fixed factors, and the last five as continuous covariates.

Table 3: Dependent Variable: Revpart (Fees per partner [expressed in $€ M]$ ])

\begin{tabular}{|l|l|l|l|l|l|}
\hline Source & $\begin{array}{l}\text { Type III Sum } \\
\text { of Squares }\end{array}$ & Df & $\begin{array}{l}\text { Mean } \\
\text { Square }\end{array}$ & F & Sig. \\
\hline Corrected & $12.930^{\mathrm{a}}$ & 9 & 1.437 & 242.364 & .000 \\
Model & .001 & 1 & .001 & .195 & .664 \\
Intercept &. $\mathbf{0 8 7}$ & 2 & .044 & 7.352 &. $\mathbf{0 0 5}$ \\
Size & .003 & 1 & .003 & .577 & .458 \\
Type & $1.550 \mathrm{E}-005$ & 1 & $1.550 \mathrm{E}-005$ & .003 & .960 \\
Year & $\mathbf{0 4 9}$ & 1 & .049 & 8.225 &. $\mathbf{0 1 1}$ \\
Density & $\mathbf{1 8 0}$ & 1 & .180 & 30.405 &. $\mathbf{0 0 0}$ \\
Fees per non- \\
partner
\end{tabular}

a. $\quad$ R Squared $=.992$ (Adjusted R Squared $=.988$ )

The Null hypothesis (that none of the indepndent variables influence the dependent variable) was rejected. Specifically, with all predictors in the model, Size $(p=0.005)$, Density $(p=0.011)$, Fees per non-partner i.e. professional service staff $(p<0.0005)$, Hierarchy $(p=0.001)$, and Fees per Office $(p=0.010)$ significantly predicted revenue per 
partner, while Type, Year and Specialization did not. Note that in this model, we assume that each year is independent. That is, we are ignoring any possible correlations between the observations in 2005 and 2013 from the same firms. This is because some of the same firms were sampled in both years, and some were different.

Multiple comparisons is one of the problems with the above analysis, i.e. as we increased the number of hypotheses in a test (when one is considering a set of statistical inferences simultaneously) we increased the likelihood of type I errors. To try to mitigate multiplicity, the nature of the relationship can also be described by looking at the difference in means for different values of the categorical/group variables (size/ type/ year), and by looking at the size and direction of the coefficients of the continuous variables. The dependent variable was again fees per partner, the independent variable were Size (Table 4), Type (Table 5) and Year (Table 6).

\section{Table 4: Dependent Variable: Revpart (Fees per partner)}

\begin{tabular}{|l|r|r|r|r|}
\hline \multirow{2}{*}{ Size } & \multirow{2}{*}{ Mean } & Std. Error & \multicolumn{2}{|c|}{$95 \%$ Confidence Interval } \\
\cline { 4 - 5 } & & & Lower Bound & Upper Bound \\
\hline Large & $1.559^{\mathrm{a}}$ & .187 & 1.166 & 1.952 \\
Medium & $.864^{\mathrm{a}}$ & .072 & .712 & 1.016 \\
Small & $.744^{\mathrm{a}}$ & .066 & .606 & .883 \\
\hline
\end{tabular}

a. Covariates appearing in the model are evaluated at the following values: Density $=11.328921$, Feespart $=.128211$, Hierarchy $=7.640633$, Special $=.475269$.

Post hoc comparisons using the Bonferroni adjustment gave that Large was significantly different from both medium $(\mathrm{p}=0.013)$ and small $(\mathrm{p}=0.004)$, and medium and small were also statistically different $(p=0.040)$. The results presented in Table 4 confirm the Big 4 effect: i.e. they are the Big 4 because their Fees per partner are commensurately large, which also reflects the level of non-partner staff required to be funded from each partner in the largest firms. This attribute (Hierarchy) is further described in Table 6 as follows, and contributes to overall wealth/revenues.

Table 5: Dependent Variable: Revpart (Fees per partner)

\begin{tabular}{|l|r|r|r|r|}
\hline \multirow{2}{*}{ Type } & \multirow{2}{*}{ Mean } & \multirow{2}{*}{ Std. Error } & \multicolumn{2}{|c|}{$95 \%$ Confidence Interval } \\
\cline { 4 - 5 } & & & Lower Bound & Upper Bound \\
\hline Partnership & $1.049^{\mathrm{a}}$ & .057 & .930 & 1.168 \\
LLP & $1.063^{\mathrm{a}}$ & .031 & .997 & 1.128 \\
\hline
\end{tabular}

a. Covariates appearing in the model are evaluated at the following

values: Density $=11.328921$, Feespart $=.128211$, Hierarchy $=7.640633$,

Special $=.475269$.

Post hoc comparisons using the Bonferroni adjustment show that partnership was not significantly different from LLP, i.e. revenue per partner was not different based solely on the type of firm. This result implies that a firm cannot expect to achieve an increase in fees by simply switching firm type.

Table 6: Dependent Variable: Revpart (Fees per partner) 


\begin{tabular}{|l|l|l|l|l|}
\hline \multirow{2}{*}{ Year } & \multirow{2}{*}{ Mean } & \multirow{2}{*}{$\begin{array}{l}\text { Std. } \\
\text { Error }\end{array}$} & \multicolumn{2}{|l|}{$95 \%$ Confidence Interval } \\
\cline { 3 - 5 } & & & $\begin{array}{l}\text { Lower } \\
\text { Bound }\end{array}$ & $\begin{array}{l}\text { Upper } \\
\text { Bound }\end{array}$ \\
\hline 2005 & $1.044^{\mathrm{a}}$ & .026 & .989 & 1.098 \\
2013 & $1.047^{\mathrm{a}}$ & .045 & .951 & 1.143 \\
\hline
\end{tabular}

a. Covariates appearing in the model are evaluated at the following values: Density $=11.328921$, Fees per no. of prof. staff $=.128211$, Hierarchy $=7.640633$, Feesoffice $=18.024281$, Special $=.475269$.

Post hoc comparisons using the Bonferroni adjustment show that 2005 was not significantly different from 2013, i.e. CPI adjusted revenue per partner was not different across the time period. This result implies that inflation adjusted fees per partner were unchanged from 2005 to 2013. The results of Tables 4-6 suggest that variation in firm size did signifciantly affect fees per partner but that firm type and the year did not.

We extended this analysis by running a regression model test with revenue per partner as the dependent variable and the aforementioned coefficients as independent variables.

Table 7: Dependent Variable: Revpart (Fees per partner)

\begin{tabular}{|c|c|c|c|c|c|c|}
\hline \multirow[t]{2}{*}{ Parameter } & \multirow[t]{2}{*}{ B } & \multirow{2}{*}{$\begin{array}{l}\text { Std. } \\
\text { Error }\end{array}$} & \multirow[t]{2}{*}{$\mathrm{T}$} & \multirow[t]{2}{*}{ Sig. } & \multicolumn{2}{|c|}{ 95\% Confidence Interval } \\
\hline & & & & & Lower Bound & Upper Bound \\
\hline Intercept & -.351 & .227 & -1.548 & .140 & -.830 & .127 \\
\hline [Size=Large $]$ & .695 & .211 & 3.286 & .004 & .249 & 1.141 \\
\hline [Size=Medium $]$ & .097 & .046 & 2.097 & .051 & -.001 & .194 \\
\hline$[$ Size=Small $]$ & $0^{\text {a }}$ & . & . & . & & . \\
\hline$[$ Type=0] & -.047 & .062 & -.760 & .458 & -.178 & .084 \\
\hline [Type=1] & $0^{\text {a }}$ & . & . & . & & . \\
\hline$[$ Year $=5.0000]$ & -.003 & .056 & -.051 & .960 & -.122 & .116 \\
\hline$[$ Year=13.0000] & $0^{\mathrm{a}}$ & . & . & . & & . \\
\hline Density & -.024 & .009 & -2.868 & .011 & -.042 & -.006 \\
\hline $\begin{array}{l}\text { Fees per non- } \\
\text { partner }\end{array}$ & 4.757 & .863 & 5.514 & .000 & 2.937 & 6.577 \\
\hline Hierarchy & .061 & .015 & 3.925 & .001 & .028 & .093 \\
\hline Feesoffice & .014 & .005 & 2.885 & .010 & .004 & .024 \\
\hline Special & .235 & .153 & 1.542 & .141 & -.087 & .557 \\
\hline
\end{tabular}

a. This parameter is set to zero because it is redundant.

Table 7 illustrates therefore that:

- For Fees per non-partner staff, Hierarchy, Fees per office and Specialisation, as they increase, the model predicts that Revenue per partner will increase.

- For density, since it has a negative coefficient, the model predicts that as density increases, Revenue per partner will decrease. 
We therefore observed some proxies for strategic choices that further clarify that there are some specific drivers to changes in Revenues (Fees) per partner, but it was not the 'LLP choice' (Table 5). A spread of offices, and specialisation, as well as the hierarchy, may all lead to efficiencies of operations.

This analysis also demonstrates that the total (CPI adjusted) revenues/fees for the firms within the Top 50 - over the period 2005 - 2013 - did not increase significantly (Table 6). This runs counter to some headlines in the Top 50 tables, for example the 2012 headline for the rankings: that "The top $50 \mathrm{UK}$ accounting firms have broken the $£ 10 \mathrm{bn}$ revenue figure for the first time, performing well despite ongoing tough economic conditions". Not so, we suggest. However, we were unable to measure whether net profit per partner and (any assumed) lower insurance costs might result in greater net profitability.

The second part of this analysis asks: did the reduction of liability and (conjectured) cheaper insurance permit a reduction in audit fees and therefore the proportion of revenues earned from specialised audit activities would reduce compared with total revenue, based on accounting firm data? For this analysis we did not take a sample of the Top 50 firms, but instead examined all the top 50 firms which provided the data under the same (or very close) firm name) in both 2005 and 2013. This resulted in an analysis based on the percentage of fees derived from audit activity compared with other revenue streams, from 31 firms.

\section{Change in the proportion of overall fees revenue/income from auditing}

\section{Table 8: Report of percentage change in fees from audit revenues split between LLP firms and Partnerships}

\begin{tabular}{|l|c|r|r|r|r|r|}
\hline TypeN2005 & Mean & \multicolumn{1}{|c|}{$\mathrm{N}$} & Std. Deviation & Minimum & Maximum & \multicolumn{1}{c|}{ Median } \\
\hline Partnership & 4.1978 & 18 & 7.44379 & -5.70 & 18.65 & 2.1848 \\
LLP & -3.9329 & 13 & 5.55796 & -15.48 & 1.83 & -1.9032 \\
Total & .7882 & 31 & 7.77105 & -15.48 & 18.65 & -.5147 \\
\hline
\end{tabular}

The change in percent of total income from the provision of audit services was significantly different for the partnership and LLP firms (as at 2005). This was statistically significant $(F(1,29)=11.025, p=0.002)$. This suggests one or more of the following was true:

a. That firms were able to lower their audit fees with the lower insurance expense

b. That limited liability firms were able to increase client revenues from other revenue streams, becoming less specialised, compared with partnerships

c. Price competition in the audit market increased for LLP firms as the clients were more wary of the reduced protection of the limited liability

d. Client firms were prepared to pay more for an audit undertaken by a firm where their liability was not limited 
This suggests there are further research opportunities based on similar or other data, especially supplementing such findings with qualitative sources such as interviews with partners or audit committees.

Table 9: Report of percentage change in fees from audit revenues analysed by size

\begin{tabular}{|l|r|r|r|r|r|r|}
\hline Size & \multicolumn{1}{|c|}{ Mean } & \multicolumn{1}{|c|}{$\mathrm{N}$} & Std. Deviation & Minimum & Maximum & \multicolumn{1}{c|}{ Median } \\
\hline small 8.20 - 11.90 & 2.4526 & 10 & 8.59095 & -13.04 & 18.65 & 1.3125 \\
medium 12.00 - 34.90 & 1.1122 & 10 & 5.21964 & -5.70 & 13.32 & -.3917 \\
large 50.30 - 1568.00 & -1.0196 & 11 & 9.15169 & -15.48 & 16.42 & -2.2680 \\
Total & .7882 & 31 & 7.77105 & -15.48 & 18.65 & -.5147 \\
\hline
\end{tabular}

The size labels in this Table refers to the 2005 ERevenue data. This indicates that the change in percent of revenue from audit was not statistically different by size. $(F(2,28)=$ $0.519, \mathrm{p}=0.601$ ).

\section{Discussion and Conclusion}

\section{Limitations}

One limitation of the analysis of proxies for strategic activity is that there may be better proxies for particular firms, depending on what information is available through case studies or analysis of web-site data. Narrative on Websites may offer clues to more specific strategic positioning by particular firms, thereby providing more firm-specific attributes. A further limitation is that the impact of this shift to LLP have occurred earlier than 2005, but we found that data earlier than 2005 was increasingly restricted in scope. We also did not take into account the impact of firm mergers on strategic choices, dispersion, hierarchy etc.

Another major limitation is that not all impacts are measurable in revenues and wealth maximisation strategies. This applies particular to the analysis of the percentage of revenues attributable to audit activity. We were unable to measure net profit per partner and lower insurance costs may reflect in great net profitability. Furthermore, the reasons for some firms retaining a partnership form may derive from the personal choices of partners, rather than any strategic or profitability motivation. However, and notwithstanding such limitations, we offer this analysis as an innovative step towards better understanding of how the mid-tier and large firms may balance up their risk avoidance and strategic positioning with offering services which better meet the public interest.

\section{Discussion and Conclusion}

As the intent was to reduce risk for any type of professional partnership, the concerted drive by the Big 4 firms to force the UK government to permit LLP structures for professional accounting firms is paradoxical to, even a counter-indicator of, the entrepreneurial spirit of professional firms described by Hopwood (1985); where risk is 
embraced as an opportunity to gain marginal revenues in competition with other similar service firms. Any anticipated rush to switch to an LLP structure did not occur and some firms in the Top 50 in the UK prefer to remain as partnerships whilst others adopt a choice of forms such as franchise, Limited Company or Association. The availability of firm data from the Top 50 analysis provided annually by Accountancy Age allowed us to also examine whether or not total (CPI adjusted) revenues for the firms within the Top 50 would increase over the period 2005 - 2013, given that insurance costs for LLP firms would not increase as much as other expenses. The answer to this was no.

We were also able to provide an analysis of proxies for associated strategic choices that further clarified the specific drivers to changes in Revenues (Fees) per partner and the 'LLP choice'. We were able to identity proxies for strategic choices that clarify there are some specific drivers to changes in Revenues (Fees) per partner, but it was not the 'LLP choice'. A spread of offices, and specialisation, as well as the degree of hierarchy, may all lead to efficiencies of operations and wealth enhancement. Part two of this study was embarked upon in order to determine if reduction of liability and a conjectured less expensive insurance would permit a reduction in audit fees, and therefore the proportion of revenues earned from specialised audit activities would reduce, compared with total revenue, based on accounting firm data. The analysis was able to describe that the change in percentage of income from audit activities/ total revenues was different for the partnership and LLP firms over the period 2005 - 2013. We offered some explanations for this, but it is clear there are further research opportunities to investigate this further, in particular with qualitative sources such as interviews with partners or audit committees.

Institutional theory focuses upon how organizations enhance their survival by converging around socially legitimated forms, and requires both identifying and also explaining structural variations among the Top 50 accounting firms. This study offers a step in this direction. Taking data from the Top 50 accountancy firms in the UK provided a method of analysing the impact of structural changes after an expansion of structural choices, and it is hoped that further research will take the opportunity to extend these findings with data from other jurisdictions where such information is publically available. It will be extremely valuable to our understanding of how the mid-tier and largest accounting firms serve any public interest, if at all, when they pressure governments for legislation in their favour. We hope other researchers will take up this challenge to previous perspectives on firm success and growth of large accounting, and other service, firms in the UK and elsewhere.

\section{References}

Anon, 1996a Limited Liability Partnerships - Protecting Partners from Armageddon. Accountancy (16 Jan.), Vol. 117 Issue 1229, p 6

Anon, 1996b. Sting in the tail for Jersey LLPs Accountancy (12 Dec.), Vol. 118 Issue 1240, p. 7

Anon, 1998. Jersey enacts LLP law at last. Accountancy International. (16 June) Vol. 121 Issue 1258, pp. 14-18.

Anon, 1999 LLP Bill - Set-back for liability campaign. Accountancy International. June 99, Vol. 123 Issue 1270, pp.12-13. 
Anon, 2009. Mergers Loom as Firms Struggle to Grow. Accountancy Age (18 June) pp. 1318.

Anon, 2012. The Big Four auditors - Accountable: Two controversies ensnare the Big Four The Economist http://www.economist.com/news/finance-andeconomics/21567953-two-controversies-ensnare-big-four-accountable

Boatright, J. (2007). 'Reluctant guardians: the moral responsibility of gatekeepers', Business Ethics Quarterly, 17(4), pp. 613-632.

Cearns, K. (2014) “If In Doubt... “Accountancy. Vol. 153 Issue 1451, pp. 8-9.

Competition Commission (2013). Statutory Audit Services Market Investigation http://www.competition-commission.org.uk/our-work/statutory-audit-services, viewed April 5th 2013.

Davies, J., (2001). Insight - LLPs - Safety in numbers. Accountancy Age (29 March)

Empson, L., and C. Chapman (2006). "Partnership versus corporation: Implications of alternative forms of governance in professional service firms." Research in the Sociology of Organizations 24 (2006), pp. 139-170,

Empson, Laura. 2012 "Beyond dichotomies: a multi-stage model of governance in professional service firms." Handbook of research on entrepreneurship in professional services (2012), p. 274.

European Parliament (2011). Report on Audit Policy: Lessons from the Crisis. Committee on Legal Affairs, Brussels, European Parliament, 2011/2037(INI).

Financial Times (1996), Financial Times, 3 July, p. 7.

Fisher, L. (2004) "Firms on the defensive. Accountancy. July 2004, Vol. 134 Issue 1331, pp. 24-25.

Freedman, J. (2000) "Limited Liability Partnerships in the United Kingdom - Do They Have a Role for Small Firms." J. Corp. L. 26 (2000), p. 897.

Grant, P. (2010), Top of the Pile. Accountancy Age. 6/17/2010, p13-16.

Greenwood, R. and R. Suddaby (2006). 'Institutional entrepreneurship in mature fields: the Big Five accounting firms', Academy of Management Journal, 49(1), pp. 27-48.

Greenwood, R., and L. Empson. 2003 "The professional partnership: Relic or exemplary form of governance?" Organization Studies 24.6 (2003), pp. 909-933.

Hansard 1996. House of Commons Debates, Hansard, Col. 617, $7^{\text {th }}$ November.

Hawkes, Alex. 2006 Avoidance Pays. Accountancy Age. 6/29/2006, p18

Hickson, D., C. Hinings, C. Lee, R. Schneck, and J. Pennings (1971). 'A strategic contingencies theory of intraorganizational power', Administrative Science Quarterly, 16(2), pp. 216-229.

Hinks, G. (2007). Audit is the top earner. Accountancy Age. 6/7/2007, p4

Hinks, G. (2008) (no title) Accountancy Age. 5/22/2008, p12-14

Hopwood, A. (1985). Accounting and the domain of the public: Some observations on current developments, Price Waterhouse Public Lecture on Accounting, University of Leeds, 1985, reprinted in A.G. Hopwood (ed.), Accounting from the Outside. London: Garland, 1988. 
Huber, N. (2009). 3,000 jobs lost in top 50 firms as recession hits financial services. Accountancy Age. 6/18/2009, pp. 3-6

Lennox and Li, (2012). The consequences of protecting audit partners' personal assets from the threat of liability, Journal of Accounting and Economics, Volume 54, Issues 2-3, October-December pp. 154-173

Likierman, A. (1989), Professional Liability: Report of the Study Teams, HMSO, London.

Litrico, J. and M. Lee (2008), Balancing exploration and exploitation in alternative work arrangements: a multiple case study in the professional and management services industry, Journal of Organizational Behavior, Vol 29, Issue 8, pp. 995-1020.

MacKenzie, D. 2008 Abusing the Corporate Form: Limited Liability, Phoenix Companies, and a Misguided Response, A dissertation submitted in partial fulfilment of the degree of Bachelor of Laws (Honours) at the University of Otago, NZ; http://www.otago.ac.nz/law/research/journals/otago036279.pdf

March, J. G. and H. A. Simon (1958). Organizations. NY: John Wiley \& Sons.

McMeeking, K. (2009). Competition, Choice and Governance in the UK Audit Market: Interview Evidence. Institute of Chartered Accountants of Scotland.

Morris, T., and Pinnington, A. (2003) "Patterns of Profit-sharing in Professional Firms". British Journal of Management. Vol. 9 Issue 1, pp.23-39.

Murray, C., Turnor, R., Hierons, R., and Cooper, C. (2014) "Losing Its Shine". Accountancy. Vol. 153 Issue 1453, pp. 60-61.

Nelson, R. R., and S. G. Winter (1982). An evolutionary theory of economic change, Cambridge, Mass.: Belknap Press of Harvard Univ. Press.

Perry, M. (2006) "Profession slays Enron dragon as Top 50 post record revenues." Accountancy Age. 6/29/2006, pp. 1-3

Quick, C, (2001). "Headstart - LLPs - Not so great expectations". Accountancy Age (29 March) p. 26

Samsonova-Taddei, A., and Humphrey C. (2015) "Risk and the construction of a European audit policy agenda: The case of auditor liability" Accounting, Organizations and Society, 41 (1) pp. 55-72.

Shohet, P. (2007). On closer inspection. Accountancy Age. 6/7/2007, p7

Sikka, P. (2008a). 'Globalization and its discontents: Accounting firms buy limited liability partnership legislation in Jersey', Accounting, Auditing \& Accountability Journal, 21(3), pp. 398-426.

Sikka, P., \& Willmott, H. C. (2009). All offshore: The sprat, the mackerel, accounting firms and the state in globalization. In C. S. Chapman, D. J. Cooper, \& P. B. Miller (Eds.), Accounting, Organizations, and Institutions. Oxford: Oxford University Press

Sikka, P.. (2008b). "Enterprise culture and Accountancy firms: new masters of the universe." Accounting, Auditing \& Accountability Journal 21.2 (2008): 268-295.

Sikka, P. (2009a) "Financial crisis and the silence of the auditors." Accounting, Organizations and Society 34.6 (2009): 868-873. 
Sikka, P. (2009b) "Commentary on Roy Suddaby, Yves Gendron and Helen Lam "The organizational context of professionalism in accounting"." Accounting, Organizations and Society 34.3 (2009): 428-432.

Suddaby, R., R. Greenwood, and C. Wilderom. (2008). "Introduction to the Journal of Organizational Behavior's special issue on professional service firms: where organization theory and organizational behavior might meet." Journal of Organizational Behavior 29.8 (2008): 989-994.

Sukhraj, P. (2008). Growth halves as Top 50 come down to earth. Accountancy Age. 6/12/2008, p3-8

Tushman, M. and E. Romanelli (1985). 'Organizational evolution: A metamorphosis model of convergence and reorientation'. In L. Cummings and B. Straw (Eds). Research in Organizational Behavior, 7, pp. 171-222.

Van de Ven, A. H., and R. Drazin (1984). The concept of fit in contingency theory. Minn. Univ. Press pp. 1-64. Interim technical report, Minnesota University, Minneapolis Strategic Management Research Center http://www.freewebs.com/dangdinhtramen/302.pdf

Veldman, J. (2013). "Politics of the Corporation". British Journal of Management 24.S1: S18-S30.

Whittington, R., L. Cailluet, and B. Yakis-Douglas (2011). “Opening Strategy: Evolution of a Precarious Profession”. British Journal of Management. 22 (3), pp531-544.

Wild, D.. (2005). Crushing Regulation drives Audit Fee Windfall. Accountancy Age. 6/30/2005, p20-23.

Young, S.. (2000). "Limited Liability Partnerships-A chance for peace of mind." Business Law Review 21.11 (2000): 257-260. 